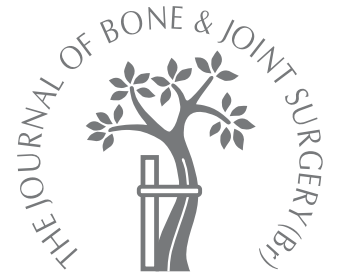

C. A. Lowry, V. B. Donoghue, C. O’Herlihy, J. F. Murphy

From the National Maternity Hospital, Dublin, Ireland
C. A. Lowry, MRCPI

J. F. Murphy, FRCPI

Department of Neonatology

V. B. Donoghue, FRCSI

Department of Radiology

C. O'Herlihy, FRCOG

Department of Obstetrics

and Gynaecology

National Maternity Hospital,

Holles Street, Dublin 2,

Ireland.

Correspondence should be sent to $\operatorname{Dr}$ C. A. Lowry;

e-mail:

lowryclodagh@hotmail.com

(C)2005 British Editorial Society of Bone and Joint Surgery

doi:10.1302/0301-620X.87B7. $16073 \$ 2.00$

$J$ Bone Joint Surg $[\mathrm{Br}]$ 2005;87-B:984-5.

Received 15 October 2004;

Accepted 16 November 2004

\title{
Elective Caesarean section is associated with a reduction in developmental dysplasia of the hip in term breech infants
}

We wished to establish whether delivery by Caesarean section influenced the incidence of developmental dysplasia of the hip in term breech infants compared with those delivered vaginally. We used maternal charts, singleton term breech presentation, mode of delivery and incidence of developmental dysplasia of the hip for births between January 1997 and October 2002.

During the study period 46089 infants were born. We analysed a total of 941 breech infants of whom 756 were delivered by Caesarean section (515 pre-labour, 241 intrapartum) and 185 vaginally. The incidence of developmental dysplasia of the hip according to the mode of delivery was 19 of 515 (3.69\%) following pre-labour Caesarean section, 16 of 241 (6.64\%) for intrapartum Caesarean section and 15 of $185(8.11 \%)$ after vaginal delivery. There was a lower incidence of developmental dysplasia of the hip among those infants delivered by elective Caesarean section compared with those delivered vaginally $(p<0.02)$. These results demonstrate a significantly lower incidence of developmental dysplasia of the hip in term singleton breech births delivered by elective, pre-labour Caesarean section and suggest that labour and delivery influence hip stability in predisposed infants.

Breech presentation is an important risk factor for developmental dysplasia of the hip (DDH). ${ }^{1-4}$ It is understood that the presentation rather than mode of delivery is the critical factor in promoting dislocation. ${ }^{5}$

The obstetric management of term singleton breech deliveries has been greatly influenced by the results of the Term Breech Trial in 2000. ${ }^{6}$ This study concluded that reduced perinatal morbidity is associated with term singleton breech births undertaken by elective Caesarean section. In 2001, the Royal College of Obstetrics and Gynaecology published guidelines supporting this conclusion. ${ }^{7}$ It was our clinical impression that since this change in delivery policy there was a reduction in the number of breech infants with DDH.

This study examined whether the mode of delivery plays a role in DDH in term singleton infants presenting by the breech.

\section{Methods}

All normally-formed singleton term infants presenting by the breech ( $\geq 37$ weeks gestation) between January 1997 and October 2002 at the National Maternity Hospital were included. For each infant the maternal parity, birth weight, gender and breech type (extended or flexed) were recorded.
For each breech birth, the mode of delivery was categorised as vaginal, emergency caesarean section in labour or elective pre-labour Caesarean section. For each breech infant, the records were examined to identify those with DDH and correlate them with mode of delivery.

During the study period all breech infants whose hips were clinically normal had an additional hip ultrasound examination at six to eight weeks of age using the Graf technique., ${ }^{8,9}$ Any additional cases of DDH identified by ultrasonography were related to the mode of delivery.

\section{Results}

During the 70-month period 46089 infants were born in the National Maternity Hospital, of whom 941 fulfilled our inclusion criteria. There were 756 deliveries by caesarean section and 185 vaginal births.

Of the 941 infants, 47 had clinical evidence of DDH and a further three were identified at eight weeks of age by ultrasound. There were 20 bilateral dysplasias, 16 right hip only and 14 left hip only. The breech classification comprised 39 extended, four flexed and seven unspecified. There were 38 girls and 12 boys. Among the mothers, 42 were primiparous and 
Table I. Relationship between the mode of delivery and the incidence of developmental dysplasia of the hip (DDH) in term breech infants

\begin{tabular}{lll}
\hline Mode of delivery & Number of infants & Number of DDH (\%) \\
\hline Vaginal & 185 & $15(8.11)$ \\
Emergency Caesarean & 241 & $16(6.64)$ \\
Elective Caesarean & 515 & $19(3.69)$ \\
Total & 941 & $50(5.31)$ \\
\hline
\end{tabular}

eight multiparous. The mean birth weights for the infants with DDH according to delivery category were: $3.33 \mathrm{~kg}$ (2.43 to 4.02 ) vaginal, $3.43 \mathrm{~kg}$ (2.89 to 4.07$)$ emergency Caesarean, $3.79 \mathrm{~kg}$ (2.84 to 4.77) elective Caesarean.

Table I illustrates the relationship between DDH in breech infants and mode of delivery. The DDH incidence among vaginal breech births was 15 of 185 breech births $(8.11 \%)$, compared with 16 of $241(6.64 \%)$ for emergency Caesarean sections and 19 of $515(3.69 \%)$ for elective prelabour Caesarean sections.

The incidence of DDH was significantly different between breech infants delivered vaginally and those delivered by elective Caesarean section $(8.11 \%$ vs $3.69 \%$; p < 0.02; chi-squared 5.75).

\section{Discussion}

Our findings indicate that the mode of delivery influences the incidence of DDH in infants in breech presentation. Those delivered vaginally had an incidence more than double that of breech infants delivered by pre-labour Caesarean. The relationship between breech presentation, mode of delivery and DDH has previously been studied with varying conclusions. ${ }^{10-12}$ In a study of 583 breech deliveries, Clausen and Nielson ${ }^{10}$ found no difference in the frequency of DDH when comparing those delivered by Caesarean section and those delivered vaginally. They did not, however, divide their Caesarean population into emergency and elective groups as we have done, thereby demonstrating higher rates of DDH in the vaginal delivery group.

We suggest the force of labour on the fetal hip contributes to DDH. Further support of this concept was suggested by Moore ${ }^{13}$ who held that repeated or forceful neonatal hip examination may lead to hip dislocation. He maintained that stretching the joint capsule was the likely cause and occurred particularly during the second part of Barlow's test when the examiner attempts to dislocate the femoral head. In a multicentre analysis of perinatal risk factors for hip dysplasia, Chan et $\mathrm{al}^{1}$ noted higher rates among infants delivered vaginally.

The resting intrauterine pressure is 4 to $5 \mathrm{mmHg}$ but during the active phase of labour this can increase to as much as $100 \mathrm{mmHg},{ }^{14}$ which possibly contributes to the increased rates of hip dislocation in the vaginally-delivered group. Pressure may cause a hip, already susceptible to dislocation by virtue of ligamentous laxity to dislocate. However, pressure alone does not explain the acetabular dysplasia associated with dislocation in some infants. We confirmed a higher rate of dislocation among girls, which is long recognised and possibly related to increased joint laxity in response to maternal hormones such as relaxin. ${ }^{3,15}$

When considering the birth weights of breech infants with DDH, we found the heavier infants were in the group with the lowest incidence of DDH (elective Caesarean section). We know from previous studies that the incidence of DDH is greater among larger babies. ${ }^{1}$ Our observations exclude the possibility that higher birth weights among the babies delivered vaginally could explain the greater incidence of DDH.

We calculate that for every 1000 term singleton breech presentations there would be 81 cases of hip dislocation if all were delivered vaginally compared with 37 if all were delivered by elective caesarean section. This represents a $54 \%$ reduction in DDH. In Ireland, with approximately 60000 births per year, one would expect approximately 1800 breech presentations at term. If all these infants were delivered by elective Caesarean section one could expect to prevent 80 cases of DDH per year. This not only represents a major financial benefit but also indicates the magnitude of the mechanical effects of labour on the hip joint in term breech cases.

Our study indicates that the mode of delivery has a significant influence on the incidence of DDH and, furthermore, gives additional insight into the aetiology of $\mathrm{DDH}$, particularly the importance of mechanical factors.

No benefits in any form have been received or will be received from a commercial party related directly or indirectly to the subject of this article.

\section{References}

1. Chan A, Caul KA, Cundy PJ, Haan EA, Byron-Scott R. Perinatal risk factors for developmental dysplasia of the hip. Arch Dis Child 1997;76:94-100.

2. Yiv BC, Saidin R, Cundy PJ, et al. Developmental dysplasia of the hip in South Australia in 1991: prevalence and risk factors. J Paediatr Child Health 1997;33:151-6.

3. Wilkinson JA. Prime factors in the etiology of congenital dislocation of the hip. J Bone Joint Surg [Br] 1963;45-B:268-83.

4. Wynne-Davis R. Acetabular dysplasia and familial joint laxity: two aetiological factors in congenital dislocation of the hip: a review of 589 patients and their families. $J$ Bone Joint Surg [Br] 1970;52-B:704-16.

5. Hsieh YY, Tsai FJ, Lin CC, Chang FC, Tsai CH. Breech deformation complex in neonates. J Repro Med 2000;45:933-5.

6. Hannah ME, Hannah WJ, Hewson SA, et al. Planned caesarean section versus planned vaginal birth for breech presentation at term: a randomised multicentre trial. Lancet 2000;356:1375-83.

7. Royal College of Obstetrics and Gynaecology. Clinical green top guidelines: the management of breech presentation, $2001 \mathrm{http}$ ///www.rcog.org.uk.asp? Page ID=153 (accessed 25/5/05).

8. Graf R, Tschauner C, Klapsch W. Progress in prevention of late developmental dysplasia of the hip by sonographic newborn hip 'screening': report of a comparative follow-up study. J Paed Orthop 1993;2:115-21.

9. Graf $\mathbf{R}$. The diagnosis of congenital hip-joint dislocation by ultrasonic compound treatment. Arch Orthop Trauma Surg 1980;97:117-33.

10. Clausen I, Nielson KT. Breech position, delivery route and congenital hip dislocation. Arch Obstet Gynecol Scand 1988;67:595-7.

11. Cole WG. Screening for congenital dislocation of the hip in Australia. J Pediatr Child Health 1991;27:143-6.

12. No authors listed. Screening for the detection of congenital dislocation of the hip Arch Dis Child 1986;61:921-6.

13. Moore FH. Examining infants hips: can it do harm? J Bone Joint Surg [Br]1989;71-B: 4-5.

14. Symonds EM, Symonds IM. Essential obstetrics and gynaecology. Fourth ed. Edinburgh etc: Churchill Livingstone, 2003:151-69.

15. Dunn PM. Congenital postural deformities. Br Med Bull 1976;32:71-6. 